\title{
The Prospects of Accounting at Mining Enter- prises as a Factor of Ensuring their Sustainable Development
}

\author{
Tatiana Tyuleneva ${ }^{1, *}$ \\ ${ }^{1}$ T. F. Gorbachev Kuzbass State Technical University, 650000, Kemerovo, 28 Vesennyaya street, \\ Russian Federation
}

\begin{abstract}
One of the problems of sustainable development of mining companies is attracting additional investment. To solve it requires access to international capital markets, in this context, enterprises need to prepare financial statements with international requirements based on the data generated by the accounting system. The article considers the basic problems of accounting in the extractive industries due to the nature of the industry, as well as evaluation of the completeness of their solution in the framework of international financial reporting standards. In addition, lists the characteristics of accounting for mining industry, due to the peculiarities of the production process that need to be considered to solve these problems. This sector is extremely important for individual countries and on a global scale.
\end{abstract}

\section{Introduction}

The mining industry is directly connected with the use of natural resources - minerals, therefore, this sector is extremely important for individual countries and on a global scale. The technological revolution that swept the developed world, has led to a increase in the consumption of diverse minerals. Therefore, there is the difficulty of securing mineral and energy resources of the global economy. For most mining companies complex task of cost reduction is not novelty: in recent years, the industry has tried to solve a number of problems of sustainable development, one of which was the need of investment in infrastructure development [1].

Russia's accession to the WTO greatly enhances the investment, but at the same time increases competition from foreign organizations, which in turn determines the necessity of creation of high-quality reporting according to international standards, which will act as a source of information for assessing the efficiency of investment [2]. In these circumstances, it is important to identify and solve the problem of accounting in the Russian mining companies as a source of information for managerial decision-making and enable sustainable development [3].

\section{Theory of experimental research}

\footnotetext{
* Corresponding author: kta.bua@kuzstu.ru
} 
Analysis of existing normative documents of different countries and scientific developments in the field of accounting in the mining sector indicates the absence of an integrated approach that takes into account all the peculiarities of this sphere. Companies use either the uniform standards of accounting and reporting, or separate national standards and recommendations which do not cover the whole range of problems [4, 5]. This situation is typical for the UK, Australia, Nigeria, Canada [6]. Even in the accounting system of the USA - the only national system, which now has quite extensive experience in accounting in mining companies - has not been sufficiently considered, taking into account the specificity of activity of mining enterprises [7].

Traditionally, IFRS` financial statement of companies was distinguished by the presence of such characteristic in the balance sheet as proven reserves resources in the section "Non-current assets" and "Liabilities on the withdrawal of assets from operation".

The main problems of standardization of accounting in the mining sector arise in connection with such key features as the uncertainty of prospects of development of deposits, a significant amount of the necessary costs at the initial stage, the time from mineral exploration to production and implementation, a significant amount of financial obligations for reclamation and for the withdrawal of production assets and infrastructure of the operation, difficulty of assessment and uniformity in the classification of reserves, most of the production facilities at the end of the period of development of the field have no residual value and a number of others [8].

Despite the fact that mining is an important industry for the global economy in recent years, standard-setters have paid little attention. International financial reporting standards before the end of 1990-ies did not contain any specific standards or review to the accounting in the mining industry [9]. The scope of the IFRS 6 "Exploration for and evaluation of mineral resources" is rather limited and covers the costs incurred by the company after obtaining the rights for the implementation of complex of works on search, evaluation and exploration and to confirm the economic viability of field development. Improvements in accordance with the provisions of IFRS 6 , are quite limited and involve a lot of conventions $[10]$.

All costs incurred during exploration and evaluation of mineral resources can be reflected in the: statement of profit and loss as an expense; balance sheet in the form of an asset.

The initial cost of the assets on the balance sheet is formed in the capitalization of costs incurred. There are 6 examples of such costs in the IFRS standard (IFRS): acquisition of exploration rights; topographical, geological, geochemical and geophysical studies; exploratory drilling; digging of the pit; selective control; work related to evaluating the technical feasibility and commercial validity of extracting mineral resources.

Of course, the above list is not exhaustive and an entity may identify other exploration for and evaluation that meets the criteria for capitalization as assets. This criterion is considered as the degree of affection of a certain type of costs to specific mineral resources. For example, the costs of obtaining seismic data may not represent a close connection with a certain resource, sufficient for their capitalization as an asset. Emergence of IFRS (IFRS) 6 divided the cost accounting for three phase boundary between given activities and the activities for exploration and evaluation is considered the moment of obtaining legal rights to explore a specific area. Only in rare cases, the cost of exploration and evaluation may include costs incurred in the implementation of the activities preceding the exploration phase and evaluation. As a rule, during this period costs cannot be capitalized, because in general, mineral resources are hypothetical in nature (IFRS 6).

But in some countries the process of obtaining a license is less formal character than in Russia, for example, in some African countries is often a substantial part of the activities of exploration begins already during the completion of the necessary formalities for obtaining a license on the basis of reasonable expectations. In such cases, the entity will consider 
whether this type of cost recognition criteria as an asset at "the Conceptual framework for IFRS".

The boundary between exploration and development passed the time when it becomes apparent technical feasibility and commercial viability of extracting resources. The term "design" has a traditional association with IAS 38 "Intangible assets", defined as "the application of research results or other knowledge in a plan or design for the production of new or substantially improved materials, components, products, processes, systems or services before the start of commercial production or use" (IAS 38). In the context of industry practice development means a phase when an identified mineral resource prepared for industrial production. For example, the construction of railways (access) to mine the mineral resource.

Develop and evaluate assets should be classified based on the nature, plant and equipment and intangible assets (IFRS 6). Some assets will include fixed assets (vehicles, drilling rigs), while others are clearly intangible assets (license). Also there will be other assets which are difficult to classify, and probably a significant portion of these other assets would consist of costs incurred in the process of construction of exploration wells or mines.

In such cases, the asset classification may be useful to answer the following question: in creation of what object sent to the specified cost object having a physical form, or to obtain information (e.g., exploration well likely to be an intangible asset, because it leads to certain knowledge). Based on the classification of assets, an entity selects accounting policies of the valuation of assets after their recognition and the disclosure of relevant information.

Unclear to date is the recognition of borrowing costs, resulting in a period of exploration and evaluation. From our point of view, borrowing costs are not the costs of exploration and evaluation at its core, therefore, it is necessary to follow IAS 23 "Costs of borrowings". A company can capitalize borrowing costs in the cost of qualifying assets. Qualifying asset is an asset whose preparation for intended use or sale requires significant time. Generally, these are assets that can be created as a result of large-scale development projects and construction.

Borrowing costs that are directly attributable to the acquisition, construction or production of a qualifying asset may be capitalized only if there is a high probability that as a result of these costs will occur future economic benefits. However, exploration is quite problematic to demonstrate the probability of future benefits.

The formation of fixed assets, intangible assets in the exploration and evaluation of resources in its content can be treated as qualifying assets. Borrowing costs that can be capitalized are those costs, the occurrence of which the company might otherwise avoid. Therefore, while there is no General exception to the borrowing costs (in relation to the costs of exploration and evaluation regarding the demonstration of probability of future benefits) it is better to capitalize only the interest on borrowed funds that are raised specifically for the acquisition of a qualifying asset (and costs on other loans that could be repaid, had it not been for the cost of the asset).

After the initial recognition of assets an entity will apply either the model of the actual cost, or the revalued amount model. We believe the first model as a priority, given that in determining the fair value of tangible assets may be missing evidence of the market value of these assets because they usually are highly specialized in nature. According to IAS 16 in the absence of evidence to support fair value, you can use the amortized replacement cost (ASP) or the profitability of the object.

Income, which an asset can generate in the future is highly uncertain, so this approach can not provide a reliable estimate of the fair value of the tangible asset. The same difficulty may arise when the revaluation to fair value of intangible assets, because an active market exists when certain conditions are met.

Assets are assessed for impairment only in cases where the facts and circumstances 
suggests that the current amount of the asset may exceed its recoverable amount. According to IAS 36: the recoverable amount of an asset represents the greater of the two values: value in use of an asset and the fair value of the asset less costs to sell; the value in use represents the discounted amount of forecasted future cash flows that should arise from the continuing use of the asset or from its disposal at the end of useful life.

The requirements for testing for impairment are applied, if possible, to each asset separately. If this is not possible, the assets typically tested for impairment in groups, called units, generating cash flows.

However, IFRS 6 provides for the possibility of some derogations from the General rules in identifying the presence of indicators of impairment:

in contrast to the procedure applied to other assets, the company is not obliged to analyze the situation to determine the presence of indications of impairment as at each reporting date until, until enough information to come to a conclusion about the technical feasibility of the extraction of mineral resources; does not oblige to test impairment at a low level (a particular geological structures, for example adjacent ore bodies); permits an entity to test for impairment, to combine (merge) one or more cash generating units (provided that the group of merged units will not be higher than the level of the union as part of the reporting segment to which the data belongs it.

Identification of cash generating units or groups of units requires the use of professional judgment and is one of the most complex areas of the audit of assets for impairment. For example, the requirement that each CGU (or group of units) was not larger than the corresponding segment should not be considered in absolute terms. Instead, consider a more objective focus on the fact that the test of impairment will not be conducted on the level at which the result of this test will be a group of assets or cash generating units included in different segments. Also, in practice, may be the preferred option to a level at which the monitored signs of impairment were consistent with the level at which estimated the recoverable amount of assets in the exploration.

The most conclusive indicator of impairment is that the rights of the company to conduct exploration work in a certain area has lost power (due to the expiration of the term), or will lose force in the near future, and thus it is not expected that these rights will be renewed (prolonged). The standard lists other symptoms involving impairment before the specified limit:

the budget is not foreseen and not planned to substantial costs for the continuation of exploration activities and evaluation in this area; the company has not discovered commercially viable deposits of mineral resources as a result up to the present time of exploration and evaluation in the area and decided to stop these operations at this site; even if the probability that it will start development of the field, is high, the company has sufficient data indicating that the carrying value of the asset is not likely to be recovered in full from successful development or sale of the asset.

The signs are determined based on the management information. If the testing for impairment of developed and assessed assets is inappropriate for the comparison of the previous reporting period, the enterprise should disclose that fact.

An entity should disclose information that reflects and explains the amounts recognised in the financial statements and related to the development and evaluation of mineral resources. Disclosure should include the accounting policies and the level at which impairment is assessed developed and assessed assets.

Many enterprises in the extractive industries has obligations to restore the site and the withdrawal of assets from operation as a result of exploration works. These commitments should also be reviewed for impairment. The obligation can either be legal (due to legal requirements), or constructive (reasonable expectations of third parties due to his past activities or public statements that it will perform this action IAS 37). With respect to the duty to 
withdraw the asset from service or the restoration of the site recognizes the reserve obligation in the full amount immediately after the occurrence of an event constituting the ground for the emergence of the obligation. For example, the relevant provision is an obligation for the anticipated cost of dismantling a test drilling rig is recognized when it is mounted.

Mining companies must apply the requirements of the standard to the costs that they have in connection with the exploration for and evaluation of mineral resources. However, for most Russian companies the most relevant stage of development.

\section{Results and discussion}

The most difficulties in applying IFRS are as follows [11].

1. Accounting for inventory and resources. In most cases, mining companies take into account only partially confirmed and proven reserves, because they believe that the unaccounted stocks associated with very large uncertainties. This decision may impact the situation when mining without significant impact to the current production plan can defer further work is required to transfer resources to reserves. Mining companies must create the conditions for consistent application of accounting policies and also demonstrate high confidence in the transfer of resources to reserves in the future.

2. The treatment of deferred costs in the open field development. Often as a result of the stripping operations company may have a double benefit: extraction of the mineral, which can be used to produce inventory and improved access to further quantities of minerals that can be mined in future periods. In cases when after the stripping activity mining company gets benefit in the form of reserves, the related costs are recognized in accordance with IAS 2 "Inventories". In cases when after the stripping activity mining enterprise benefits from improved access to deposits in the future, the related costs are recognised as an asset associated with stripping activities [12]. The experts of financial services may require additional information from the production department (project engineers, geologists, surveyors) for a deeper analysis of the costs incurred for overburden works [13]: identification of components in the composition of minerals in accordance with the plan (plans) of development of the field; unit production for the distribution of the total amount of Stripping costs between the cost of inventory produced in the current period, and the capitalized asset; - the definition of the period of beneficial use of each component mineral in order to calculate the depreciation of assets of stripping activity.

3. Long-term storage`s dumps accounting. If mining company has plans for the processing of this raw materials, the costs associated with its production, must be attributed to future periods (non-current reserves). However, this solution depends on whether management evaluates profitability using the price forecasts (at the time of processing of raw materials) or current market prices. In accordance with the international standards for determining the value of other non-current assets is usually used the principle of the time value of money.

4. Accounting of expenses on the excretion of exploitation and land reclamation. One of the specific items in financial statements of mining companies is a reserve for liquidation of fixed assets and restoration of the landscape. However, in IFRS there is no detailed guidance on its calculation, so questions on the calculation of the reserve and its annual revision, become even more relevant. Often, licenses for exploration and development of deposits do not contain clear requirements for action mining to end use of mining land, which complicates the evaluation of reserve, however, IAS 37 "Reserves, contingent liabilities and contingent assets" provides a possibility of making reliable estimates of future costs associated with the dismantling of its assets and the restoration of the deposits [14]. Use of estimates has a significant impact on the reliability of the financial statements. In the case of using the experience of other mining companies it is important to ensure the similarity of 
the mining fields, as the costs for dismantling vary depending on the production technology, the type of structure deposits, and other factors that affect the production process.

\section{Conclusion}

In the current economic circumstances, the accounting in the mining industry has the challenge - with all the features of this sector of the economy securely and reliably reflect the assets, liabilities, the facts of economic life, sources of funding, income and expenses in the financial statements. The efficiency of economic decisions taken by users of these reports in the first place, and potential investors, depends on it. Accordingly, the inflow of investment will ensure dynamic and sustainable development of the mining sector.

Currently in accounting in the mining industry, there are still many unresolved issues. It is necessary that in the framework of the IFRS be created a unified global standards for the training and reporting in the mining industry, taking into account all aspects of the industry. For countries committed to reforming their national systems in accordance with IFRS becomes relevant active part in the development of international standards. This will ensure the most efficient and high-quality preparation and presentation of the information in the financial statements, which will serve as one of the factors of sustainable development of the industry.

\section{References}

1. T. Carlin, N. Finch, Macquarie Graduate School of Manag. Work. Paper, 13, 4 (2008).

2. T. A. Tyuleneva, Europaische Fachhochschule, 6, 89 (2014)

3. E. V. Kucherova, T. A. Tyuleneva, N. A. Cherepanova, Coal in the 21st Century: Mining, Processing and Safety, 130 (2016).

4. I. Tsalavoutas, L. Evans, Managerial Auditing Journal, 25(8), 814 (2010)

5. N. H. Laili, Journal of law and financial management, 7(2), 8 (2008)

6. J. Kranc, Financial executive, 7-8, 66 (2011)

7. J.M. Langmead, J. Soroosh, The CPA Journal, 8, 24 (2012)

8. D.W. Taylor, Asian Review of Accounting, 17(1), 40 (2009)

9. E. Kvaal, C. Nobes, Accounting and Business Research, 40(2), 173 (2011)

10. G. Guggiola, The International Business \& Econ. Res. Journal, 9(12), 99 (2010)

11. A. Rahman, H. Perera, Abacus, 38, 46 (2002)

12. B.J. Epstein, E.K. Jemarkovich, Interpretation and application of International Financial Reporting Standards (John Wiley \& Sons Inc., Hoboken, New Jersey, 2010)

13. C.M. Graziano, E.M. Heffes, Financial Executive, 25(1), 17 (2009)

14. A. Jaruga, J. Fijalkowska, M. Jaruga-Baranowska, M. Frendzel, Accounting in Europe, 4(1), 67 (2011) 